\title{
Prosilience trajectories of phoenix regions: a narrative on intelligent transformation of old mining areas
}

\author{
Patricio AROCA*, Karima KOURTIT**, Peter NIJKAMP***, \\ Roger STOUGH $\dagger^{* * * * *}$
}

\begin{abstract}
This paper departs from the regional resilience concept - as part of a broad strand of literature on non-linear dynamic systems in a space-economy - and introduces the notion of prosilience to highlight the policy challenge of developing radically new and innovative strategies for regions in decline. The mining industry will be used as an illustrative case. The notion of phoenix regions is put forward to argue that an external disruption or shock in an established industrial sector in a region necessitates unconventional survival strategies oriented towards entirely new market demands and based on totally different product packages. Ansoff's model on product diversification in competitive markets forms an inspiration source for the Schumpeterian 'creative destruction' proposition advocated in this study. An illustrative case study is concisely described in the present paper, viz. the SouthLimburg coal mining region in the Southern part of the Netherlands. Smart prosilience trajectories supported in particular by evidence-based decision support tools are sketched for such depressed regions, based on the so-called Pentagon intervention model. The paper is concluded with some general policy lessons for an intelligent transformation of regions in decline.
\end{abstract}

Keywords: resilience, prosilience, phoenix regions, intelligent transformation, mining areas, Ansoff model, creative destruction, sustainable development

\footnotetext{
* Patricio AROCA is Professor at the CEPR, Universidad Adolfo Ibáñez, Viña del Mar, Chile; e-mail: patricio.aroca@uai.cl.

${ }^{* *}$ Karima KOURTIT is Researcher at the Open Universiteit, Heerlen, The Netherlands; Alexandru Ioan Cuza University of Iasi, Romania; Mohammed VI Polytechnic University, Benguerir, Morocco; e-mail: k_kourtit@ hotmail.com.

*** Peter NIJKAMP is Professor at the Open Universiteit, Heerlen, The Netherlands; Alexandru Ioan Cuza University of Iasi, Romania; Mohammed VI Polytechnic University, Benguerir, Morocco; Adam Mickiewicz University, Poznan, Poland; e-mail: pnijkamp@hotmail.com.

${ }^{* * * * *}$ Roger STOUGH (George Mason University, Fairfax, WV, USA) passed away on Thursday, September 6, 2019.
} 


\section{Resilience and prosilience in the life cycle of industrial phoenix regions}

A phoenix is in the old Greek mythology a sign of hope. It is a bird which arises from the ashes and hence symbolizes a new future after a decline or catastrophe. The question whether there is 'life after death' has puzzled not only theologians and philosophers, but also social scientists addressing the causes of decline of nations or communities and the conditions for a recovery (see e.g. Olson, 1982; Jacobs, 1961). In the past decades several strands of literature have focused the attention on the indeterminate and non-linear dynamic - often fluctuating pattern of multi-actor interactive systems. Examples are inter alia: cybernetics (Wiener, 1948), systems theory (Forrester, 1961), catastrophe theory (Thom, 1975), chaos theory (Nijkamp and Reggiani, 1992), bifurcation theory (Kielhofer, 2012), synergetics (Haken, 1983), auto-poiesis (Maturana and Varela, 1991), theory of selforganizing systems (Yates, 2012), agent-based theory (Bonabeau, 2002), complexity theory (Reggiani and Nijkamp, 2009), and more recently the resilience theory (Okuyama and Rose, 2019).

Despite marked differences in the above mentioned theoretical and methodological frameworks for the analysis of dynamic systems, they also share various common features, such as: an interest in robust development opportunities of dynamic systems brought out of balance, a search for intervening actors, especially those with leadership (Stimson et al., 2009) and/or entrepreneurship (Stough and Nijkamp, 2007; Stough, 2016) capacity or policy handles so as to steer the evolution of a complex interdependent system, the recognition of the indeterminate or often unpredictable character of living and human systems, and so forth. These analysis frameworks have found many applications in social science disciplines, such as political science, management science, sociology, psychology, geography and economics.

It is noteworthy that in the history of economic thinking the concept of equilibrium has played a central role, starting from an abstract mathematical analysis by Walras (1874) and proceeding to computable general (spatial) equilibrium modelling (see e.g. van den Bergh et al., 1996). Other seminal contributions to dynamic and life cycle trajectories in economics can be found in innovation theory, starting from Schumpeter (1942) with his core notion of 'creative destruction', and proceeding to modern contributions on the 'economic fate' of nations (Acemoglu and Robinson, 2012).

Regional science has definitely played an active role in the analysis of nonlinear, dynamic and complex systems (see e.g. Reggiani and Nijkamp, 2009). In recent years, the emerging concept of 'resilience' has gained much popularity (Martin 2012; Reggiani et al., 2002; Borsekova and Nijkamp, 2019; De Siano et al., 2020; Stough, 2018). There is no doubt that resilience has become one of the cornerstones for analysing the complex evolution of regions or cities (Benazić and Tomić, 2020; Batabyal and Kourtit, 2021; Modica and Reggiani, 2015; Modica et 
$a l ., 2019)$. It has in recent years inspired many publications on sustainable or balanced spatial growth. In the context of regional resilience studies, we refer here inter alia to Cere et al. (2017); Christopherson et al. (2010); Martin and Sunley (2015); Ibanescu et al. (2020); Pavel et al. (2020); Pascariu et al. (2020); and Wojtowicz (2020).

The academic interest among planners and policy-makers in the recovery potential of a spatial system, once brought out of its initial equilibrium position, is booming, but has sometimes also witnessed a rather narrow scope by addressing the following oversimplified resilience question: how to restore the original equilibrium? In many empirical regional case studies however, the core question is not whether a region or city - after a perturbation or shock - should be brought back towards its starting point, but whether it should rather be put on a new trajectory towards a more promising and even higher performing future state. And therefore, we introduce here the complementary concept of 'prosilience' to articulate the need for innovative and creative development strategies that would prompt an economically healthy and sustainable future of a system in transition. This prosilience approach is thus inspired by the phoenix phenomenon introduced in this paper.

In the light of the above observations, the present paper introduces the concept of prosilience as an analytical departure for the study of regions in decline (as a result of external shocks, market forces or government interventions). It seeks to develop creative and innovative prospects for such problem regions by using the inherent traditional resource potential of the region concerned as a stepping stone for a radically new development trajectory based on an intelligent transformation with the help of knowledge-based high-tech strategies. In the empirical part of our paper, we will - as a meaningful illustration - zoom-in on promising novel opportunities for old mining areas facing a stage of decline. Using our phoenix approach, we will explore whether a structural economic decline may become - through a 'creative destruction' - a 'blessing in disguise' by being forced to adopt and implement radically new perspectives for the declined area concerned. After a concise overview of the literature and an introduction to the South-Limburg region in the Netherlands, we will distil general lessons from this old coal mining region for regions in decline.

The present study is organised as follows. After this introductory section, Section 2 will address conversion problems of old industrial areas from the perspective of a prosilience-based intelligent transformation of these areas. Next, in Section 3 we will sketch the methodology of smart reconversion of declining areas based on an extension and amendment of the so-called Ansoff model. Section 4 will then be devoted to a short description of the phoenix development in a regional setting, the South-Limburg coal mining region in the Southern part of the Netherlands, followed by a sketch of a prosilience trajectory. In Section 5, we will draw lessons from this 'phoenix region' for prosilience strategies, using a 
methodological resilience approach based on the 'Pentagon model'. The paper will be concluded with general policy guidelines and lessons.

\section{Declining industrial areas and prosilience-based intelligent transformation}

\subsection{Tidal movements of industrial areas}

In their opus 'Why Nations Fall - The Origins of Power, Prosperity and Poverty', Acemoglu and Robinson (2012) raise the question why some economies are high performers and others are losers. According to the authors, institutional quality, especially economic support and incentives for competitiveness, is decisive for a successful and vital economy. This message, heralded already 30 years earlier by Olson (1982), has not lost its relevance in times of economic recession and pandemic crises. The quality of governance systems is not only of critical importance for the poverty (or prosperity) level of a nation, but also for the welfare position of regions (Dijkstra et al., 2020).

Since its inception, regional science has concentrated much attention on lagging or less privileged regions by tracing the determinants of lower levels of welfare of some regions, by seeking to explain why certain regions fail and others survive, and by exploring effective policy options to improve the socio-economic fate of depressed regions (Capello and Nijkamp, 2019). A glance at some structurally underperforming areas (e.g., the Mezzogiorno, the Apalachian region, the SubSahara region, parts of India etc.) may give the impression that regional science - as the science mainly concerned with severe problems of regional development - is a 'dismal' science (in the negative sense expressed by the British social scientist Thomas Carlyle), where in a Malthusian spirit the resources on earth are never able to provide a decent quality of life for all people. However, there are also great examples of highly successful regional economies, e.g. Catalonia, Northern Italy, the Randstad Holland, California, Japanese regions, Dubai and so forth. And in addition, there are fluctuating regions which follow the uncertain tidal movements of the economy (e.g. Detroit, Andalusia, various Greek urban regions, regions in Brazil, and so forth). Regional science is clearly about the evolution and governance of an ever changing regional-economic landscape. In this context, regional innovation capacities, institutions, leadership and entrepreneurship are some of the key factors behind a significant endogenous growth based on knowledge, where space and distance play an important role in promoting or recovering a region (Karlsson et al., 2014).

\subsection{The fate of old mining areas}

The scientific literature on mining areas, especially from a resource extraction perspective (including ore, minerals and iron extraction) is vast. For example, even 
several centuries before the emergence of the Industrial Revolution (mid-nineteenth century), coal mining was already an established, rather flourishing economic activity in many countries. The high energy needs of many new industrial sectors (e.g., the steel industry) prompted most emerging large industries to locate near coal mining or resource areas (e.g., the Ruhr Area, the Borinage, the British coal mining areas, Pittsburgh etc.). And many of these mining regions became - due to their abundant natural resources - in these times the wealthiest areas in the national economy. With the rise of more abundant alternative energy resources all over the world (oil, natural gas, and at present green energy), the dominant role of most coal mining areas started to decline. And especially in the post-WWII period many old coal mining regions became gradually problem regions, partly because of the fierce competition with other energy resources and partly because of the poor image caused by often inferior work circumstances in the mines. In the past half a century, an extensive scientific literature has been published on social science and regional aspects of the mining industry. In a noteworthy and informative publication, Karakaya and Nuur (2018) provide an extensive informed overview of 483 systematically selected papers on mining with a social science orientation, including the geographical aspects and the most popular social science research topics related to the mining sector. The authors observe a remarkable shift from traditional research foci (industrialization, economic base, resource dependency) to contemporary topics (mining cluster, sustainable supply chain, safety and liability conditions, corporate responsibility) (Atienza et al., 2016; Batterham, 2014; Segerstedt and Abrahamsson, 2019).

Nowadays, the mining industry in general is confronted with a rapidly rising materials market (industry, electronics, automotive industry, energy, infrastructure etc.), in which high-quality raw materials are getting increasingly scarce. But, in contrast, the coal mining industry - as a source of fossil fuels - seems to reach more and more the end of its current life cycle. Mining projects are characterized by a long start-up period, and there are hardly new coal mining initiatives in the developed world. Clearly, new technological advances may make (coal) mining more sustainable and safer, but the investment requirements and ecological challenges are still formidable; despite the shared-value and open-innovation concepts, the end of the coal mining industry seems to be in sight (Asr et al., 2019), in particular since sustainability requirements in the area of environmental quality, health, safety and social conditions are hard to meet (Madsen, 2009). Responsible coal mining - a critical guiding principle in the general mining industry - is often a too ambitious goal. Consequently, an intelligent transformation of the coal mining industry seems to be a wise - and necessary - strategy, not only for the coal mining industry, but also for the regions involved.

In general, from a business perspective, coal mining projects should be feasible from an economic, social, ecological and territorial perspective. Given their long-range impacts, a structured life cycle management of the development of such 
projects is a sine qua non, in particular, in regard to the foreseen end-of-life-cycle trajectory in the coal mining sector in the decades to come. Pro-active strategic views on new pathways (e.g., employability of miners, restoration of ecosystem services, plant diversity and soil stability (Bekendam and Pöttgens, 1995)) are thus to be developed from a prosilience perspective. In this context, ecosystem tourism, mining tourism and geotourism may be part of the new roadmap for regions confronted with mine closure and completion (Conlin and Jolliffe, 2011; Armis and Kanegae, 2019; Y1ldız, 2021). Mining areas might become new tourist attractions. It seems thus clear that in particular coal mining areas are in need of a drastic, sustainable and intelligent transformation in the near future.

\subsection{Lands of hope and glory? A resource-based capability approach}

The above life-cycle interpretation of the evolution of the (coal) mining industry prompts the need for innovative development strategies (or smart industrial adaptation), as was argued above in the context of a prosilience perspective on the mining sector. Undoubtedly, such drastic changes may turn out to lead to a deplorable economic, social and ecological disaster, if the necessary painful transformations are put in operation in a too late time period in the industry's life cycle. The Schumpeterian view on 'creative destruction' needs also a timely proactive response. This calls for a future-oriented sustainable business model to be activated in time (see also Section 3). But an important element is also the fact that mining companies - and public bodies - should start strategic transformative actions well ahead in time, so as to use and transform the mining area as a new source of innovative business opportunity (Bryant, 2015). Clearly, a necessary economic, ecological and technological radical change in the core business of a region is not necessarily a socio-economic disaster. Any perturbation or shock in the resource base of a region may provide new development opportunities. Such a 'blessing in disguise' view on economic growth (see Borsekova and Nijkamp, 2019) may open up new economic prospects. This positive perspective on regional development is inspired by Sen's (1979) capability approach. In this analysis framework for new development opportunities, the economic 'fate' of a country or region is not exclusively determined by the limiting presence of territorial resources, but also by its innovative and effective use of these resources in a competitive environment (Nijkamp 2018, 2020). Impediments and barriers may thus act as important stimuli for an innovative and smart transformation of a region. This also holds for old (coal) mining regions. In the next section, we will use Sen's capability approach as a stepping stone to Ansoff's model of industrial strategy. 


\section{Life after death: Ansoff revisited}

In the history of the theory of industrial organization the so-called Ansoff model has often played a prominent role (Ansoff, 1957). The Ansoff-model is essentially a conditional growth model for firms and describes the dynamic and fluctuating life cycle pattern of a single firm that starts as a 'lonely player' on the market, but gradually acquires a stronger position as an important and mature player in a competitive market. Fierce competition in a growing market however, forces the firm to diversify and innovate its products so as to keep or obtain a rising share of the total sectoral production. Thus, after the take-off phase of a business activity, the new firm tends to 'sell more of the same to the same people', by employing low-risk standard marketing channels. When competition grows, the firm will first try to sell more of the same to new clients or to new spatial markets, based on a short-sighted medium-risk strategy. To maintain or expand its market share in a more competitive environment, the range of products or services may be extended by producing and offering new variants of the initial products or services. This calls for a more forward-looking and creative business attitude characterized by a medium-term, medium-risk strategy of the firm. Finally, if the competitive behaviour of other firms follows the successful modus operandi of the original entrepreneur, the project initiator may either face a situation of decline or develop a new business model with entirely new products and services for new market segments. The latter innovative diversification strategy is based on a long-term, high-risk business model. The above mentioned four business strategies can be depicted as follows (Figure 1).

\section{Figure 1. Pictorial description of the Ansoff model}

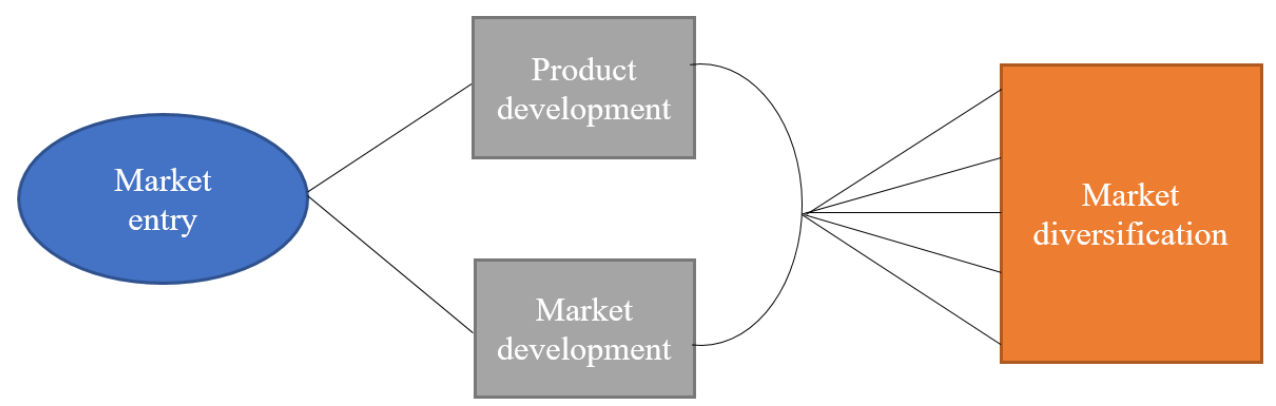

Source: Authors' representation

It is noteworthy that the Ansoff model is not a deterministic growth model. Firms which fail to respond actively and properly to new challenges or opportunities will stay small or leave the business. This is in agreement with Sen's capability theory: actors with an innovative and intelligent mindset will have the highest 
chances to survive or to win. There is not one linear future trajectories, but a whole bundle from which the most promising one will have to be chosen. In Ansoff's seminal contribution, various development trajectories of the firm are depicted (e.g., slow growth, decline, cyclical growth), depending on the firm's response to external challenges (e.g., technological breakthrough, economic downturn or upturn, war situations, political uprise, natural catastrophes etc.). This means that the 'economic fate' of the entrepreneur depends on generic factors (leading to stable trend forecasts), uncontrolled perturbations or shocks (leading to contingency forecasts), and firm responses to external challenges (leading to individual challenge-response strategies). In case of a higher degree of diversification, business firms tend to be less vulnerable to external factors and hence to be more resilient. In case of proactive business intelligence, firms may be able to choose a prosilient development strategy (which may ultimately lead to 'planning for the unknown'). This is particularly critical in case of a 'phoenix' strategy.

It goes without saying that the Ansoff business development model for individual entrepreneurs cannot simply be transposed to the evolution of the mining sector, for several reasons: (i) there is often no single or unambiguous mining entrepreneur; (ii) mining is normally firmly embedded in the regional economic structure, which makes it less flexible in adjusting to new industrial strategies; (iii) the mining industry is traditionally operating in a monopolistic competition field and is thus less alert to changes; (iv) any change in a regionally dominant mining industry tends to have far-reaching labour market consequences, which makes the sector rather inert and less adaptive; (v) mining industries are often forming a broadly composed industrial cluster, while a total conversion of a structural cluster is usually fraught with almost unsurmountable problems (see Gordon and Kourtit 2019, 2020). The most distinctive feature of the mining industry however, is that it does not have close substitutes, so that a smooth product diversification is only possible to a very limited degree. Consequently, if a (coal) mining region wants to change its product orientation in the light of changing market circumstances, it has to identify and develop radically new strategies, production portfolio's and business trajectories (e.g., high-tech, pharmaceuticals, tourism). From this perspective, especially the evolution of coal mining industry in a given region is at the end of its life cycle and calls for rigorous transitions, driven by 'smart creative destruction' in relation to intelligent and prosilient transformation. This is schematically depicted in Figure 2, which presents a package of new actions inn case of a 'phoenix' ambition of a declining region. 
Figure 2. Pictorial description of adjusted Ansoff model for a (coal) mining region.

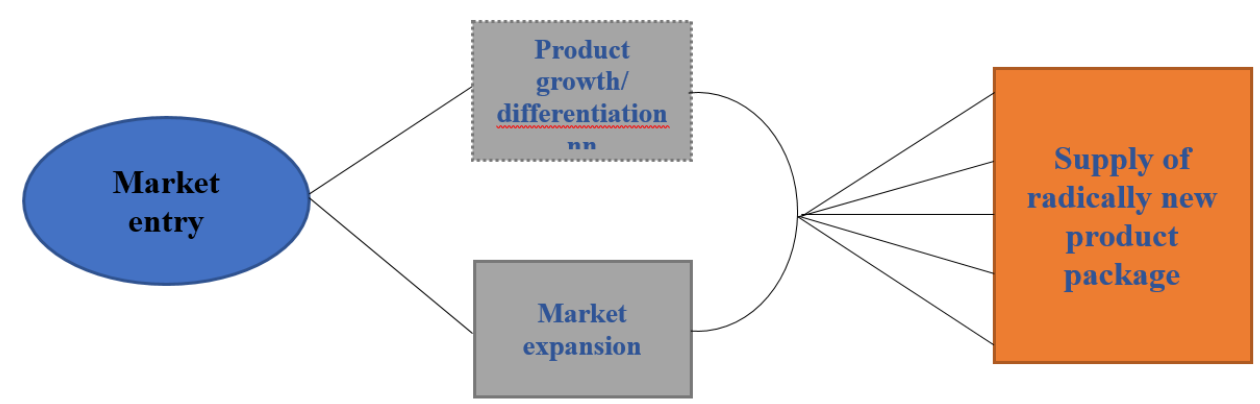

Source: Authors' representation

Nowadays, the coal mining industry world-wide does not have favourable prospects. It is mainly a low-tech, low-skilled economic sector. It is noteworthy that Bryant (2015) has identified the following key forces and trends in the mining industry in general:

- An ongoing demand for resources, despite short-run fluctuations;

- A rapidly rising concern on the sustainability consequences of mining;

- An intensification of geo-political tensions and community activism regarding mining activities;

- Increasing difficulties in constructing, operating and closing mining industries;

- Structural underinvestment in technology and innovation in the mining sector (and their regions).

It should be added that the mining industry is usually embedded in a broad regional industrial cluster which is often historically determined and is hence rather rigid in its adaptability to new challenges. The latter feeble characteristic of the mining industry makes this sector vulnerable in case of drastic transitions, as lack of innovation and creative foresight may lead to serious fallbacks or decline in case of drastic changes (Basu and Kumar, 2004; Bertayeva et al., 2019). The coal mining industry operates nowadays in a dynamic and uncertain force field. The decreasing interest in fossil fuels and the relatively low technological innovativeness in this sector do not open many promising perspectives for this industry. In several countries in the past decades, rigorous attempts have been made to develop alternative development strategies for those coal mining areas that most likely were bound to close down their activities. In the sequel of this paper, we will present findings and lessons from prosilience policy strategies for a former coal mining area from the Netherlands. In this case new policy directions were identified and envisaged so as to explore a promising prosilient future of a former mining region. 


\section{The South-Limburg coal mining area in the Netherlands}

\subsection{History and context}

Coal mining in Limburg, the most Southern province of the Netherlands, has already a long history. The first coal mining activities in this isolated area date back to the $16^{\text {th }}$ century, but the real commercial - and later on largely state-owned exploitation and production of the coal mines in South-Limburg started after the Industrial Revolution. The beginning of the $20^{\text {th }}$ century heralded the age of coal as a major energy source in the Netherlands. South-Limburg became one of the wealthiest regions in the Netherlands, in which 'mine barons' - often originating from other provinces or foreign countries - generated prosperity and exhibited a luxury life style. We refer to some geographical information on this region in the map in Figure 3.

\section{Figure 3. Map of South-Limburg}

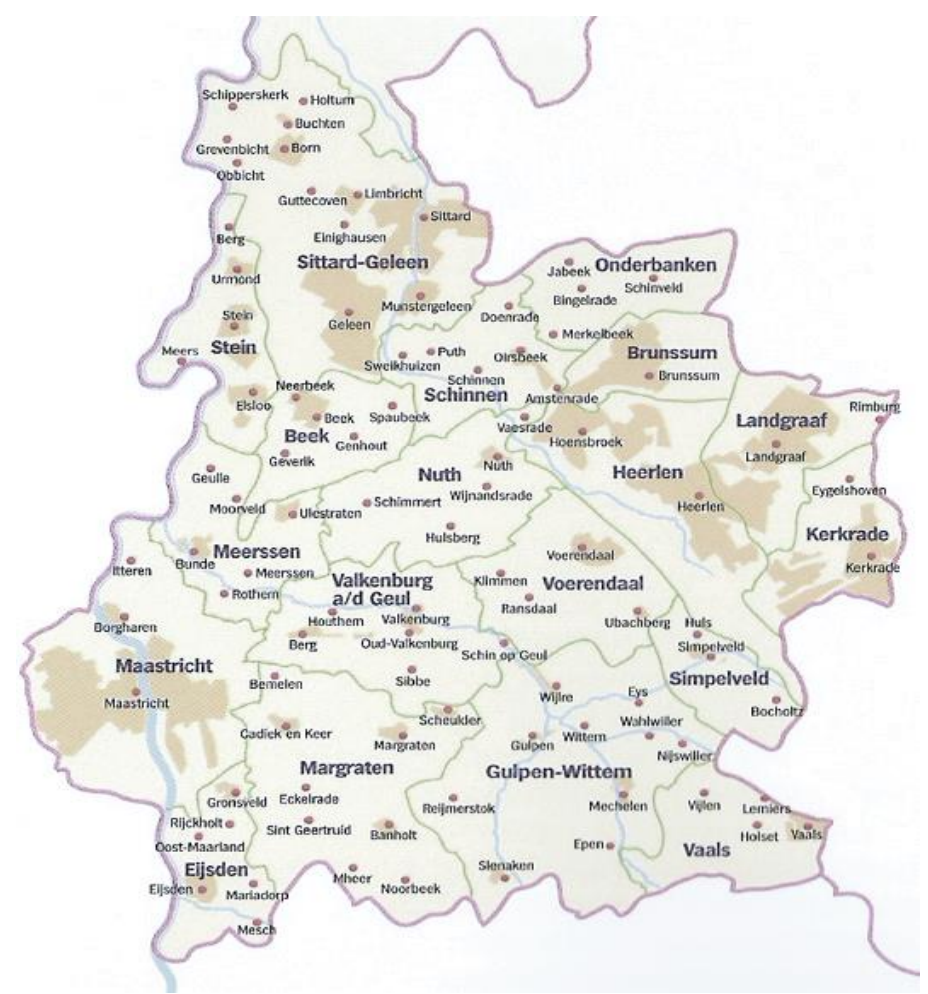

Source: Limburg ${ }^{1}$

${ }^{1}$ Limburg.nl (retrieved from https://www.limburg.nl/over/kaarten-cijfers/). 
This situation changed drastically when in December 1965 the Dutch government decided - given the problematic prospects for coal mining - to close down all mines in South-Limburg in a rapid pace. The coal mine production was economically not viable anymore, as: (i) imported coal (mainly from the USA and South Africa) had a more favourable price-quality ratio; (ii) the Netherlands had in the 1960s discovered almost unlimited natural gas reserves in its own territory (in the North); (iii) oil became increasingly a relatively cheap substitute; (iv) the safety and health risks in mining activities were rather high. This decision had serious consequences for the labour market, as the mining industry is a low-skilled industry. Adaptation to other new industrial opportunities was almost impossible, and hence the region turned into a problematic high-employment area. Consequently, the peripheral area of South-Limburg (in particular, around Heerlen and Kerkrade near the German border) went through a major economic decline, with an excessively high unemployment rate from the 1970s onwards.

\subsection{Challenges and responses}

The government tried to compensate for the loss of jobs after the final mining closures (in 1974), inter alia by shifting major public services to this area (e.g., creation of a new public university in Maastricht, foundation of the Open University in Heerlen), location of (a significant part of) the national Central Bureau of Statistics in Heerlen, as well as a shift of the Civil Servants' Pension Fund (ABP) and of the Taxation Office (Belastingdienst) to the same area. In addition, various private companies were encouraged to (re-)locate or expand their activities in this area (e.g. DSM, DAF). But a serious mismatch on the regional labour market continued to exist, as the newly created jobs were often not available in the area concerned. It took several decades before the tidal movement turned into a more favourable development: the painful transition from a former rather prosperous, low-skilled industrialised regional economy to an advanced booming and internationallyoriented service- and knowledge-based complex (e.g. pharmaceuticals) took almost half a century. As a consequence, in the meantime the South-Limburg area lost a significant part of its labour force and population (especially from the younger and highly educated cohort), whereas its share of the elderly is above the national regional average.

The former Dutch coal mining region in South-Limburg was mainly concentrated around the cities of Heerlen, Kerkrade and Brunssum. Even nowadays the far-reaching impacts of the mining closure are still visible, as this area is still characterized by a relatively high degree of unemployment, impoverishment, low level of cultural amenities, and low access to tertiary and higher education, and a low level of domestic innovativeness. Despite a significant state support for this 
depressed area since the end of the 1960s, the economic perspectives remained over this long period rather unfavourable. The provision of new jobs took much more time than anticipated and as a result of the accelerated closure of mines and of delays in offering new jobs, the region ended up in a serious socio-economic downturn. A shared and committing prosilience strategy was never developed by the stakeholders, and after the accompanying economic downturn from the 1970s the possibilities to become a phoenix region were very limited. The region became a typical example of a 'region in decline', with low economic and innovative performance and with a weak labour market achievement.

The government made several plans for a re-industrialisation of the province of Limburg, by offering tax facilities, investments loans, etc.; by relocating public agencies to the South; by improving infrastructure; by offering educational and training programmes; and by providing social support (e.g. early retirement). There is no doubt that in the first phase (1965-1980) the stakeholders (national government, regional and local authorities, mining companies, unions etc.) were full of good intentions. Later on, the feeble elements of the restructuring policy (no concerted view among stakeholders; mismatch between supply and demand on the regional labour market (Håkansson and Bejakovic, 2020; Sevinc et al., 2020); ineffective and inefficient use of public subsidies) were more explicitly recognized, and this led to an erosion of the support for the necessary economic transformation measures. However, in the meantime, one company, namely DSM (the successor of the former Dutch State Mines), has become a glaring example of a successful modern multinational chemical company, while gradually in recent decades the pharmaceutical, the knowledge, and the distributional sector has gained quite some importance.

The awareness has grown in recent years that a strategic re-profiling and reconfiguration of the total regional economy needs relatively high public investments (e.g., roads, railways, airports, cultural facilities, educational institutions, medical care facilities, sports facilities, tourist attractions). From this perspective, the situation in South-Limburg is not significantly different from many European regions in decline, in particular:

- long-time delays in effective and successful economic transformation;

- unfocussed spending of public subsidies and expenditures, with much emphasis on new jobs and less on coping with emerging unemployment;

- less emphasis on radical innovations and development and on the use of advanced or high-tech activities.

It is noteworthy however, that in the past decade, the socio-economic situation in the former mining area in Limburg has gradually improved. One might speculate that the phoenix model has begun to materialize, albeit with a slow speed. But it is also clear that a clear vision on a prosilient future of the region is still in its infancy. In the next section we will outline the contours of such a strategic view by 
introducing and articulating a novel strategic development concept in SouthLimburg, called Smart HILLS.

\subsection{Prosilience analysis}

The development of the region under consideration has to be seen against the background of its historical and current strong features. The province of Limburg has an interesting long history, dating back to the Roman period and an ecologically rich structure, with big and small rivers and with a characteristic green hilly landscape that is unique in the Netherlands. The mining industry in South-Limburg was precisely located in this region and has meant a significant environmental change and ecological decay. It is therefore no wonder that any radical transformation of this region from an industrial area to a modern sustainable area should respect its precious historical and environmental conditions and opportunities. Given its ecological beauty, South-Limburg has in the meantime also become an attractive tourist destination, so that in a future-oriented conversion programme also tourist and ecological attractiveness should be taken into consideration. Thus far, several new initiatives have been launched over the past decades, albeit without a clear, unambiguous and consistent future view. Also, various distinct industrial programmes have been set up, e.g., in the area of distribution logistics, tourism and pharmaceuticals. But a coherent and attractive programme, with a clear commitment of all stakeholders, has as yet not materialized.

It should also be noted that the peripheral position of South-Limburg - a region bordering both Germany and Belgium - may also be seen as a 'blessing in disguise', as this triangular area is characterized by a very favourable accessibility to the German city of Aachen (a major knowledge, technological and industrial centre) and the Belgian city of Liège (a major industrial and logistic centre), apart from a close vicinity to Maastricht (a major knowledge and service centre with a historical importance). This entire border region cross-cutting three countries is called the 'Euregio' in an EU context. The main challenge for this area is to develop a strategic future-robust programme in the post-corona age (in terms of competitive service delivery, advanced industrial production (e.g. pharmaceuticals, logistic distribution, shared knowledge production, tourist attractiveness, ecological value, healthy living and working, etc.).

A solid and prosilient new roadmap for this old mining area in decline needs - in the spirit of our adjusted Ansoff model - a pro-active and committed effort of all stakeholders and a flexible adjustment to new circumstances, in which resources from the past (industrial entrepreneurship) are linked to opportunities for the future (advanced, competitive and knowledge-based service production). The close vicinity of various academic and applied knowledge institutions, the broad and varied industrial base of the region, the internationally accessible location, and the historical and unique ecology of the area offer many options for a promising and radically new 
future. A necessary condition would be to solve the qualification gap on the labour market, so that new initiatives correspond to the indigenous labour market composition (Sevinc et al., 2020)

Recently, as a result of a shared consultation and concerted commitment of representative leaders from the public, the public and the knowledge sector, a new ambitious and future-resistant research, policy and action programme was developed, with the acronym Smart HILLS (Smart Heerlen Intelligent Limburg Leadership in Sustainability). This is meant to become a smart policy-action and support portfolio for sustainable urban and regional development in the wider SouthLimburg area (including its cross-border linkages). It is knowledge-based, which means that advanced data analytics - as a sine qua non for managerial strength, spatial resilience and innovative power - is a signpost for prosilient policy-making.

The main challenge for regional development of South-Limburg is to find a fit-for-purpose life-cycle pattern on the generic regional prosilience trajectory. This calls for a mobilisation of all territorial resources (knowledge, infrastructure, organisational capacity) so as to upgrade the regional growth potential and to develop a 'phoenix' development (Figure 4).

\section{Figure 4. The regional prosilience trajectory of a phoenix region}

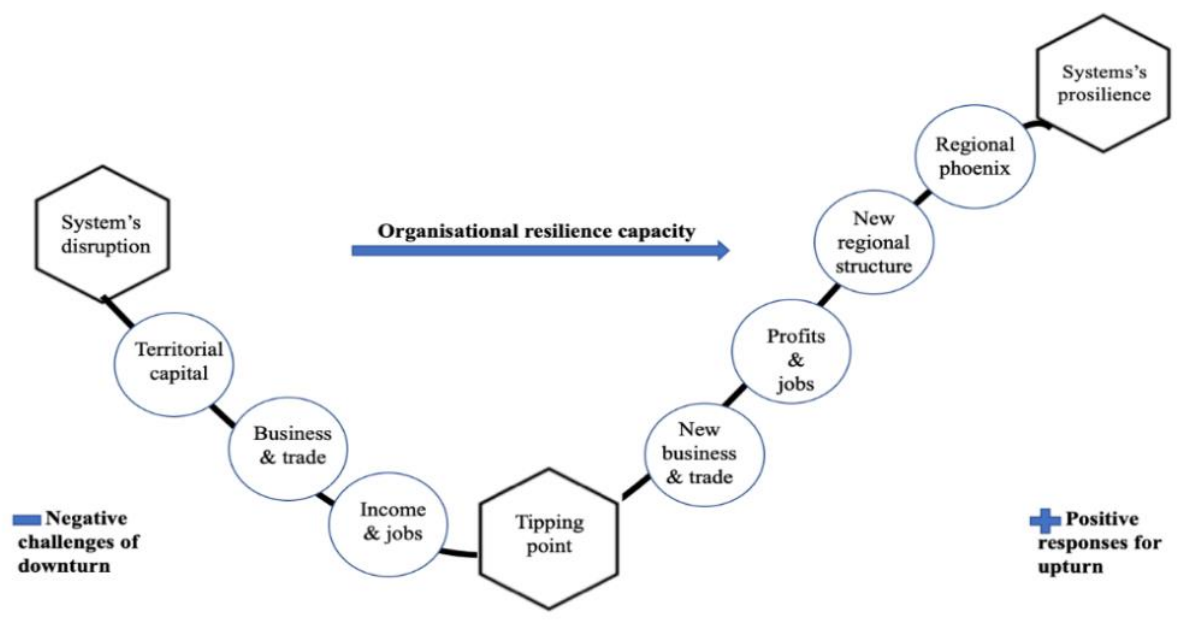

Source: Authors' representation

Smart HILLS is a framework for a coherent and knowledge-based development for South-Limburg, in which regional sustainability is achieved by smart and digital-technology inspired strategies. It shares the following features:

- Concerted interaction between government bodies, industrial sector, knowledge institutions and citizens ('quadruple helix'); 
- Focus on modern data science methods (including big data, AI, machine learning, data mining) as the cornerstones for intelligent transformation;

- Focus on smart specialisation (e.g., pharmaceuticals, distribution logistics, tourism) in the broader regional economic structure in the Euregio triangle area;

- Phase-wise development and implementation of various strategic initiatives. Examples are: (i) Smart Climate HILLS; (ii) Smart Healthy HILLS; (iii) Smart Cultural HILLS; (iv) Smart Knowledge HILLS, etc. All these initiatives are based on a promising merger of high-tech/digital-data expertise with strong local or territorial resources;

- Design of a user-oriented advanced monitoring, communication and steering system on the basis of transparent, accessible and interactive policy support dashboards in order to stimulate sustainable development in both the Heerlen agglomeration (Regio Parkstad Limburg) and the broader Euregio area.

An informal platform representing the interest of stakeholders was created so as to pave the road for a flexible and goal-oriented realisation of the UN SDGs in the area concerned. This means a radically different modus operandi for this earlier mining area, in which regional stakeholders should share the responsibility for the sustainable development of the area under consideration. A new equilibrium pathway based on the prosilience paradigm is currently in the making. The ingredients of the policy-action and -support framework will be sketched in Section 5.

\section{Assessment: a policy-support and -action dashboard}

\subsection{A Pentagon approach}

There is an extant literature on planning support methods (Klosterman et al., 2018; Kourtit and Nijkamp, 2014; Steenbruggen et al., 2017; Wamsler, 2017). In recent years, policy-support and -action dashboards have gained much popularity (Kourtit and Nijkamp, 2019). Such dashboards have been designed and applied for a great variety of cases, for instance, global organizations (e.g. UN Habitat), government-initiated programmes, community-oriented local plans, industrial organisations, health programmes (e.g. COVID-19 monitoring) etc.

A dashboard is not only a monitoring instrument, but offers also a route guidance for balanced decisions. It usually includes a multiplicity of data that have to be systematized in order to provide transparent and accessible information for policy on different routes to be taken. The architecture has to follow a strict and unambiguous logic, where not only efforts to be made but also expected outcomes and critical limits are to be clearly articulated. A full-fledged dashboard may include in a surveyable manner several - though always limited, but focussed - policy signposts, such as ecological sustainability, resources availability and use, socioeconomic welfare indicators, health and safety data etc. It has normally a modular 
(or cascade) composition. A concise overview of the principles and structure of a policy dashboard can be found in Kourtit and Nijkamp (2017).

The following 'pentagonal' sketch of the foundation of a dashboard can be imagined (Figure 5). The foundation of this schematic picture of a sustainable development programme is formed by five critical success factors, condensed into a pentagon intervention structure (see also Section 4).

Figure 5. A Pentagon intervention structure for XXQ strategy of SouthLimburg

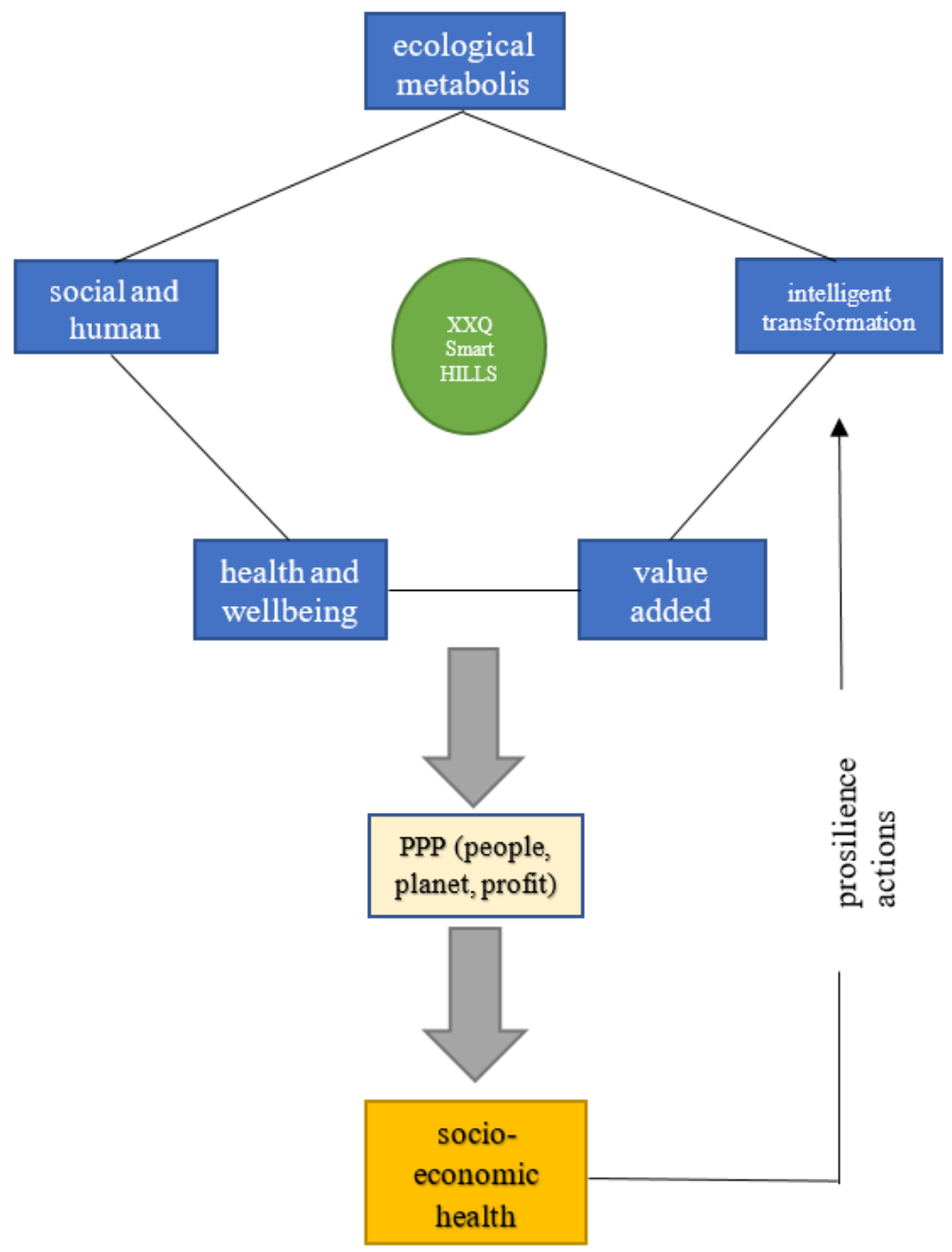

Source: Authors' representation 
These five factors form also the cornerstones for a decomposed dashboard. The assessment of the outcomes of the anticipated or realized regional socioeconomic structure takes place by using the global PPP principle (people, planet, profit) as a frame of reference. This principle works as a filter for managing and steering the regional-economic structure. The performance of this regionaleconomic 'health checks' in the dashboard as a frame of reference. In this way, the regional institutional constellation is able to realize its development goals, as summarized in the XXQ (highest possible quality achievement; see Nijkamp, 2008) of the South-Limburg region. Clearly, such a stakeholder-oriented dashboard system can be designed for each of the Smart HILLS programmes in South-Limburg as well as for the comprehensive HILLS programme. It goes without saying that organisational capacity is a critical success factor for achieving a favourable position on the prosilience curve. Hence, in the recent literature much attention is paid to organisational resilience (Kantur and Isery-Say, 2012; Limnios et al., 2014; Sawalha, 2015; Somers, 2009).

The mapping of the force field of a region in decline calls - in order to become a phoenix region - for a mobilisation and performance enhancement of all regional resources. The stepwise logic of such a structured development strategy is depicted in Figure 6. This figure maps out the successive steps in a policy analysis which serves to enhance the innovation potential of a region in decline that aspires to become a phoenix region on the basis of the logic of Figure 4 and 5. The strategic development trajectory to be followed by such a region starts from a well thought and broadly shared vision and mission statement, resorting into the common acceptance of long-range KPIs as the basis for a sustainable regional performance strategy. This calls for a systematically structured data collection which in their mutual interdependence can be captured in the pentagon model as shown in Figure 5. Next, this multidimensional set of policy-relevant data - to be stored in an openaccess data warehouse - forms the input for a policy navigation system and intervention mechanism, to be integrated in a smart policy dashboard. Such a dashboard contains thus a multiplicity of policy-relevant data on objectives which may sometimes be - or often are - mutually conflicting. Consequently, for a rational underpinning of policy decisions to be taken a systematic multi-objective programming - or multicriteria decision analysis - has to be pursued, which maps out various meaningful compromise solutions or policy directions (Nijkamp et al. 1990). Finally, the findings will be presented to an interactive forum of stakeholders who can provide their tentative views on the solution space. In many cases, there will be a need for more - or more precise - information, so that an interactive policy analysis cycle emerges, till a final compromise solution is achieved. This approach seems to be an appealing and rational model for enhancing the development potential of regions in decline, including the mining area in South-Limburg. 
Figure 6. An interactive policy dashboard architecture

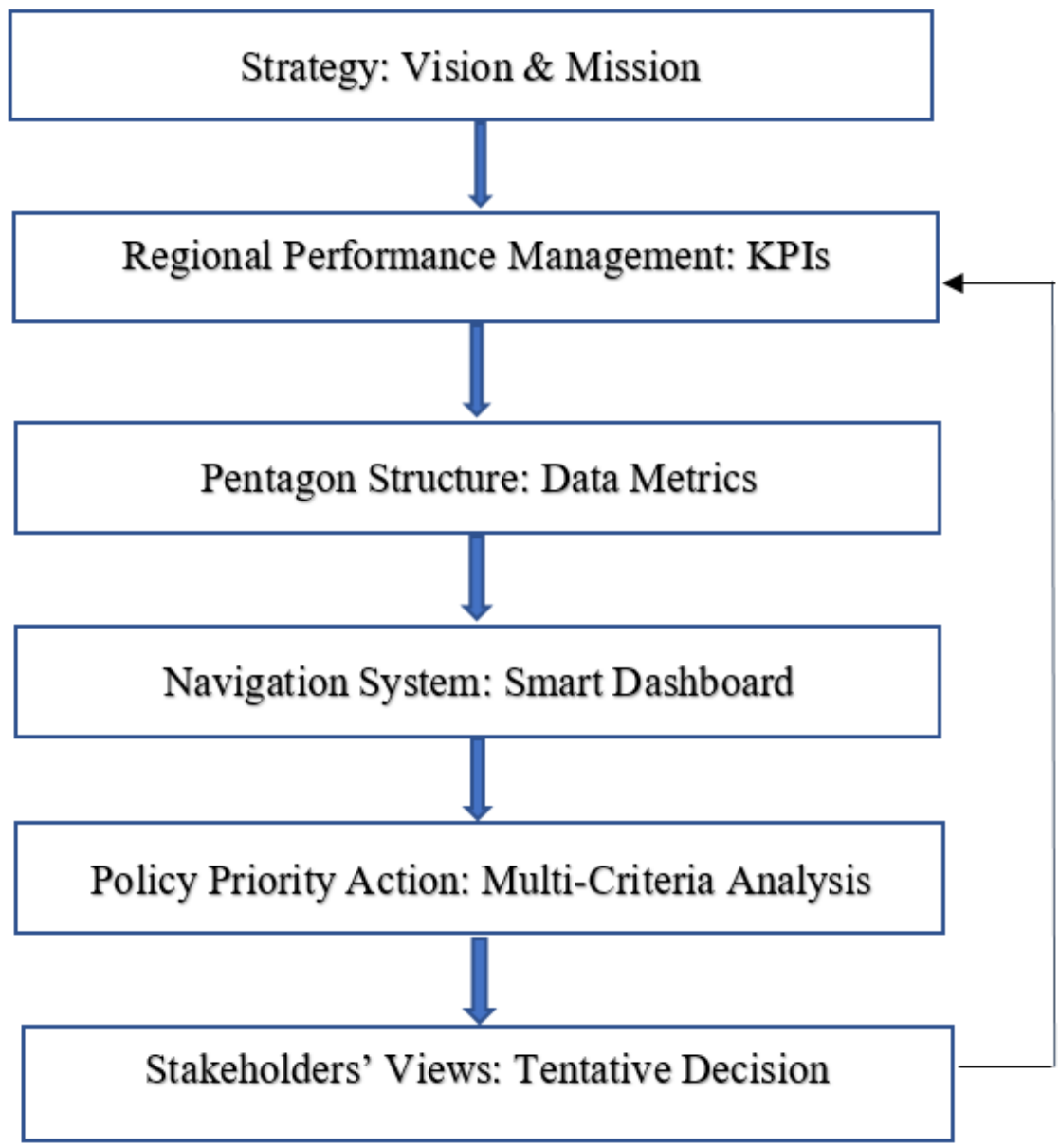

Source: Authors' representation

\section{Strategic lessons}

The goal of achieving a resilient development of old mining regions is essentially determined by the need for sustainable and innovative development of the regions concerned. If an old industrial region is in severe stress because of dramatic changes in market demand or resource technology, it needs to exploit its indigenous resources (knowledge, human resources, culture, ecology, entrepreneurial spirit, and socio-political history) to develop well in advance a radically new development strategy. Such challenges are not unique for the mining sector, but hold for many other industries and regions as well (e.g., textile, steel, 
agriculture, oil). And therefore, forwardly looking business strategies are a sine qua non for any prosilient region that wants to exploit its development capability for creating a sustainable life under severe decline conditions.

In a recent article, Duchek (2020) makes a distinction of a resilience trajectory for depressed regions into three stages: (i) anticipation (in particular, observation \& identification, and preparation), (ii) coping (in particular, accepting, developing, and implementing solutions), and (iii) adaptation (in particular, reflection \& learning, and change). This three-stage resilience action model is useful for corporate responses of firms operating in a flexible and competitive market. In the mining industry - operating for sometimes centuries in the same region - an agile and fast response in an established market is more problematic. Inert behaviour and delayed response may then lead to an irreversible decline of this particular sector. It is then the region which has to exploit all its resources to survive and to create new favourable conditions for socioeconomic revitalisation. The effective and pro-active role of public institutions and local-regional-national government policies is then of critical significance (OECD 2019). Consequently, a phoenix region does not arise automatically, but needs a dedicated policy effort based on a symbiosis of organizational-institutional resilience (Boin and van Eeten, 2013) and territorial resilience (Rizzi et al., 2018).

The development of a concerted policy strategy based on a merger of organizational-institutional and territorial resilience means the creation of a prosilient regional development strategy that is oriented towards the smart, often digital-technology oriented use of all relevant (material and immaterial) resources. The organization of regional resilience capacity needs open-minded and alert leadership and consistent and inclusive decision-making bodies, innovative and sharing attitudes of committed stakeholders, smart data analytics expertise, proactive and unifying strategic alliances (including local and regional communities), and convincing and evidence-based arguments for new phoenix strategies that serve regional interests inspired by Sen's option approach and Ansoff's choice approach.

The general lesson from this narrative of an old mining area is that permanent innovation is a key to regional success. The recent high-tech and knowledge-based oriented growth trajectory of the South-Limburg mining area demonstrates that a new perspective for a region in decline is possible, if effective prosilience strategies are put in action. Prosilience in a 'phoenix' context will only be achieved, if regional stakeholders develop a commonly shared development vision. Intelligent transformation of a region in decline calls for a sound knowledge base that guides evidence-based future trajectories. A phoenix region is not 'manna from heaven', but calls on an active involvement and deployment of all regional resources. A final word of caution is in order: the present study has offered a narrative on the tidal movement of a region in decline. This narrative was framed in the context of Sen's capability theory and Ansoff's competitive choice theory. More solid research - both 
quantitatively and comparatively - would be needed to infer solid, generic lessons on 'phoenix' strategies.

Acknowledgements: This work was supported by a grant of Romanian Ministry of Research and Innovation, CNCS-UEFISCDI, project number PN-IIIP4ID-PCCF2016-0166, within the PNCDI III project ReGrowEU - Advancing ground-breaking research in regional growth and development theories, through a resilience approach: towards a convergent, balanced and sustainable European Union. Karima Kourtit and Peter Nijkamp also acknowledge the grant from the Axel och Margaret Ax:son Johnsons Stiftelse, Sweden.

\section{References}

Acemoglu, D. and Robinson, J.A. (2012), Why Nations Fall, Profile Books, London.

Ansoff, I. (1957), Strategies for Diversification, Harvard Business Review, 35(5), pp. 113-124.

Armis, R. and Kanegae, H. (2019), The Attractiveness of a Post-Mining City as a Tourist Destination from the Perspective of Visitors, Asia-Pacific Journal of Regional Science, 4, pp. 443-461. https://doi.org/10.1007/s41685-019-00137-4

Asr, E.T., Rakaie, R., Atari, M. and Mohammadi, M.R.T. (2019), A Review of Studies on Sustainable Development in Mining Life Cycle, Journal of Cleaner Production, 229, pp. 213-231. https://doi.org/10.1016/j.jclepro.2019.05.029

Atienza, M., Aroca, P., Stimson, R. and Stough, R. (2016), Are Vertical Linkages Promoting the Creation of a Mining Cluster in Chile? An Analysis of the SMEs' Practices Along the Supply Chain, Environment and Planning C: Government and Policy, 34(1), pp. 171-187. https://doi.org/10.1177\%2F0263774X15614708

Basu, A.J. and Kumar, U. (2004), Innovation and Technology-Driven Sustainability Performance Management (ITSPM) for the Mining and Minerals Sector, International Journal of Mining, Reclamation and Environment, 18(2), pp. 125-149. https://doi.org/10.1177\%2F0263774X15614708

Batabyal, A.A. and Kourtit, K. (2021), The Use of Resilience in Regional Science: Five Outstanding Issues, in: Reggiani, A., Schintler. L.A., Czamanski, D. and Patuelli, R. (eds.), Handbook on Entropy, Complexity and Spatial Dynamics, The Rebirth of Theory?, Edward Elgar, Cheltenham (forthcoming).

Batterham, R. (2014), Lessons in Sustainability from the Mining Industry, Procedia Engineering, 83, pp. 8-15.

Bekendam, R.F. and Pöttgens, J.J. (1995), Ground Movements over the Coal Mines in Southern Limburg, Land Subsidence, $5^{\text {th }}$ International Symposium, The Hague, 234, pp. 3-12.

Benazić, M. and Tomić, D. (2020), Macroeconomic dynamics in China, Laos and Vietnam: a VAR analysis, Eastern Journal of European Studies, 11(2), pp. 203- 228. 
Bergh, J.C.J.M., van den, Nijkamp, P. and Rietveld, P. (1996), Recent Advances in Spatial Equilibrium Modelling, Springer, Berlin. https://doi.org/10.1007/978-3-642-80080-1

Bertayeva, U., Panaedova, G., Natocheeva, N., Kulagovskaya, T. and Belyanchikova, T. (2019), Industry 4.0 in the Mining Industry: Global Trends and Innovative Development, E3S Web of Conferences, 138, pp. 1-7. https://doi.org/10.1051/e3sconf/201913504026

Boin, A. and Eeten, M.J.G. van (2013), The Resilient Organisation - A Critical Appraisal, Public Management Review, 15(3), pp. 429-445. https://doi.org/10.1080/14719037. $\underline{2013.769856}$

Bonabeau, E. (2002), Agent-Based Modelling, Proceedings of the national academy of sciences, 99(3), pp. 7280-7287. https://doi.org/10.1073/pnas.082080899

Borsekova, K. and Nijkamp, P. (2019), Resilience and Urban Disasters, Edward Elgar, Cheltenham.

Braunerhjelm, P., Acs, Z.J., Audretsch, D.B. and Carllson, B. (2010), The Missing Link: Knowledge Diffusion and Entrepreneurship in Endogenous Growth, Small Business Economics, 34(2), pp. 105-125. https://doi.org/10.1007/s11187-009-9235-1

Bryant, P. (2015), The Case for Innovation in the Mining Industry, Clareo, Chicago.

Capello, R. and Nijkamp, P. (2019), Handbook of Regional Growth and Development Theories, Edward Elgar, Cheltenham.

Cere, G., Rozgui, Y. and Zhao, W. (2017), Critical Review of Existing Built Environment Resilience Frameworks, International Journal of Disaster Risk Reduction, 25, pp. 175-189. https://doi.org/10.1016/j.ijdrr.2017.09.018

Christopherson, S., Mickie, J. and Tyler, P. (2010), Regional Resilience, Cambridge Journal of Regions, Economy and Society, 3(1), pp. 3-10.

Conlin, M., and Jolliffe, L. (2011), Mining Heritage and Tourism, A Global Synthesis, Routledge, London.

De Siano, R., Sciabolazza, V.L. and Sapro, A. (2020), Regional Resilience to Climate and Environmental Shocks, Springer, Berlin.

Dijkstra, L., Poelman, H. and Rodriguez-Pose, A. (2020), The Geography of EU Discontent, Regional Studies, 54(6), pp. 737-753. https://doi.org/10.1080/00343404.2019. $\underline{1654603}$

Duchek, S. (2020), Organizational Resilience: a Capability-Based Conceptualisation, Business Research, 13(1), pp. 215-246. https://doi.org/10.1007/s40685-019-0085-7

Forrester, J.W. (1961), Industrial Dynamics, MIT Press, Cambridge, Mass.

Gordon, P. and Kourtit, K. (2019), Spatial Clusters and Regional Development, in: Capello, R. and Nijkamp, P. (eds.), Handbook of Regional Growth and Development Theories, Edward Elgar, Cheltenham, pp. 366-384.

Gordon, P. and Kourtit, K. (2020), Agglomeration and Clusters near and far for Regional Development: A Critical Assessment, Regional Science Policy \& Practice, 12(3), pp. 387-396. https://doi.org/10.1111/rsp3.12264 
Haken, H. (1983), Synergetics, Springer, Berlin.

Håkansson, P.G. and Bejakovic, P. (2020), Labour market resilience, bottlenecks and spatial mobility in Croatia, Eastern Journal of European Studies, 11(2), pp. 5-25,

Ibanescu, B.C., Eva, M. and Gheorghiu, A. (2020), Questioning the Role of Tourism as an Engine for Resilience: The Role of Accessibility and Economic Performance, Sustainability, 12(14), p. 5527. https://doi.org/10.3390/su12145527

Jacobs, J. (1961), The Death and Life of Great American Cities, Random House, New York.

Kantur, D. and Isery-Say, A. (2012), Organisational Resilience, Journal of Management and Organization, 18, pp. 762-773.

Karakaya, E. and Nuur, C. (2018), Social Sciences and the Mining Sector: Some Insights into Recent Research Trends, Resources Policy, 58, pp. 257-267. https://doi.org/10.1016/j.resourpol.2018.05.014

Karlsson, C., Johansson, B., Kobayashi, K. and Stough, R. (2014), Knowledge, Innovation and Space, Edward Elgar, Cheltenham.

Kielhofer, H. (2012), Bifurcation Theory, Springer, Berlin.

Klosterman, R., Brooks, K., Drucker, J., Feser, E. and Renski, H. (2018), Planning Support Methods, Bowman \& Littlefield, Lenham.

Kourtit, K. and Nijkamp, P. (2014), The Use of Visual Decision Support Tools in an Interactive Stakeholder Analysis, Sustainability, 5(10), pp. 4379-4405. https://doi.org/10.3390/su5104379

Kourtit, K. and Nijkamp, P. (2017), A Big Data Dashboard Architecture for a Computable Intelligent City, BDC, 17(1), pp. 23-31. https://doi.org/10.6092/2284-4732/5471

Kourtit, K. and Nijkamp, P. (2019), Big Data Dashboards as Smart Decision Support Tools for i-Cities, Land Use Policy, 71, pp. 24-35. https://doi.org/10.1016/j.landusepol.2017.10.019

Limnios, E.A.M., Mazzarol, T., Ghadounai, A. and Schilizzi, S.G.M. (2014), The Resilience Architecture Framework, European Management Journal, 32(1), pp. 104-116. https://doi.org/10.1016/j.emj.2012.11.007

Madsen, P.M. (2009), These Lives will not be Lost in Vain: Organizational Learning for Disaster in U.S. Coal Mining, Organization Science, 20(5), pp. 861-875. https://doi.org/10.1287/orsc.1080.0396

Martin, R.L. (2012), Regional Economic Resilience, Hysteresis and Recessionary Shocks, Journal of Economic Geography, 12(1), pp. 1-32. https://doi.org/10.1093/jeg/lbr019

Martin, R.L. and Sunley, P. (2015), On the Notion of Regional Economic Resilience, Papers in Regional Science, 15(1), pp. 1-42. https://doi.org/10.1093/jeg/lbu015

Maturana, H.R. and Varela, F.J. (1991), Autopoiesis and Cognition, Springer, Berlin.

Modica, M. and Reggiani, A. (2015), Spatial Economic Resilience; Overview and Perspectives, Networks and Spatial Economics, 15(2), pp. 211-233. https://doi.org/10.1007/s11067-014-9261-7 
Modica, M., Reggiani, A. and Nijkamp, P. (2019), Vulnerability, Resilience and Exposure: Methodological Aspects, in: Okyama, Y. and Pose, A. (eds.), Advances in Spatial and Economic Modelling of Disaster Impacts, Springer, Berlin, pp. 295-324.

Nijkamp, P. (2008), XXQ Factors for Sustainable Urban Development: A Systems Economics View, Romanian Journal of Regional Science, 2(1), pp. 1-34.

Nijkamp, P. (2018), The Resourceful Region, Journal of Regional Research, 36, pp. 191-214.

Nijkamp, P. (2020), Borders as Opportunities in the Space-Economy: Towards a Theory of Enabling Space, Asia-Pacific Journal of Regional Science, 5(1), pp. 223-239. https://doi.org/10.1007/s41685-021-00191-X

Nijkamp, P., Rietveld, P. and Voogd, H. (1990), Multicriteria Analysis in Physical Planning, Elsevier, Amsterdam.

Nijkamp, P. and Reggiani, A. (1992), Interaction, Evolution and Chaos in Space, Springer, Berlin.

OECD (2019), Resilience Strategies and Approaches to Contain Systemic Threats, Doc SG/NAEC(2019)5, OECD, Paris.

Okuyama, Y. and Rose, A. (2019), Advances in Spatial and Economic Modelling of Disaster Impacts, Springer, Berlin.

Olson, M. (1982), The Rise and Decline of Nations, Yale University Press, New Haven, CT.

Pascariu, G., Kourtit, K. and Tiganas, R. (2020), Spatial Resilience and the Border Regions of Europe, Regional Science Policy \& Practice, 12(5), pp. 749-754.

Pavel, A., Moldovan, B.A., Kourtit, K. and Nijkamp, P. (2020), Urban or Rural: Does It Make A Difference for Economic Resilience? A Modelling Study on Economic and Cultural Geography in Romania, Sustainability, 12(9), p. 3776. https://doi.org/10.3390/su12093776

Reggiani, A., de Graaff, T. and Nijkamp, P. (2002), Resilience: An Evolutionary Approach in Spatial Economic Systems, Networks and Spatial Economics, 2(2), pp. 211-229. https://doi.org/10.1023/A:1015377515690

Reggiani, A. and Nijkamp, P. (2009), Complexity and Spatial Networks, Springer, Berlin.

Rizzi, P., Graziana, P. and Dellara, A. (2018), A Capacity Approach to Territorial Resilience: the Case of European Regions, Annals of Regional Science, 60(2), pp. 285-328. https://doi.org/10.1007/s00168-017-0854-1

Sawalha, I.H.S. (2015), Managing Adversity, Management Research Review, 38, pp. 346366. https://doi.org/10.1108/MRR-01-2014-0010

Schumpeter, J. (1942), Capitalism, Socialism and Democracy, Routledge, London.

Segerstedt, E. and Abrahamsson, L. (2019), Diversity of Livelihoods and Social Sustainability in Established Mining Communities, The Extractive Industries and Society, 6(2), pp. 610-619.

Sen, A. (1979), Inequality of What, in: McMurrin, J. (ed.), The Tanner Lectures on Human Values, Cambridge University Press, Cambridge, pp. 197-220. 
Sevinc, D., Green, A., Bryson, J.R., Collinson, S., Riley, R. and Adderley, S. (2020), Ensuring Skills Are Available in the Right Locations, Regional Studies, 54(8), pp. 1149-1160. https://doi.org/10.1080/00343404.2020.1740190

Somers, S. (2009), Measuring Resilience Potential, Journal of Contingencies and Crisis Management, 17(1), pp. 12-23. https://doi.org/10.1111/j.1468-5973.2009.00558.x

Steenbruggen, J., Kourtit, K. and Nijkamp, P. (2017), The Significance of Digital Data Systems for Smart City Policy, Socio-Economic Planning Sciences, 58, pp. 13-21. https://doi.org/10.1016/j.seps.2016.10.001

Stimson, R., Stough, R. and Salazar, M. (2009), Leadership and Institutions in Regional Endogenous Development, Edward Elgar, Cheltenham.

Stough, R. (2016), Entrepreneurship and Regional Economic Development: Some Reflections, Journal of Regional Research, 36, pp. 129-150.

Stough, R. (2018), Learning Regions, Cluster and Resiliency: a Typology of Regional and Cluster Dynamics, in: Baycan, T. and Pinto, P. (eds.), Resilience, Crisis and Innovation Dynamics, Edward Elgar, Uk.

Stough, R. and Nijkamp, P. (2007), Entrepreneurship in Regional Economic Development: Some Methodological Applications, The Annals of Regional Science, 41(4), pp. 749752. https://doi.org/10.1007/s00168-007-0142-6

Thom, R. (1975), Structural Stability and Morphogenesis, Addison-Wesley, Reading.

Walras, L. (1874), Elements d'Economie Politique Pure, 1st ed. in two installments, Lausanne: Corbaz.

Wamsler, C. (2017), Stakeholder Involvement in Strategic Adaptive Planning, Environmental Science and Policy, 75, pp. 48-157. https://doi.org/10.1016/j.envsci.2017.03.016

Wiener, N. (1948), Cybernetics, MIT Press, Cambridge, Mass. https://doi.org/10.1002/9781118766804.wbiect041

Yates, F.E. (2012), Self-Organizing Systems, Springer, Berlin.

Yıldız, T.D. (2021), Overlapping of Mine Sites and Highway Route in Turkey: Evaluation in Terms of Mining Land Use Criteria and Land-Use Planning, Land Use Policy, 106, p. 105444. https://doi.org/10.1016/j.resourpol.2021.102241

Wojtowicz, N. (2020), Resilience against intentional shocks: a wargaming study of the relation between space, action and the residing population to resilience, Eastern Journal of European Studies, 11(1), pp. 5-26. 